\title{
Site Assessment for Astroparticle Detector Location in Evaporites of the Polkowice-Sieroszowice Copper Ore Mine, Poland
}

\author{
Jaroslaw Slizowski, Zenon Pilecki, Kazimierz Urbanczyk, Elzbieta Pilecka, \\ Leszek Lankof, and Rafal Czarny \\ Mineral and Energy Economy Research Institute, Polish Academy of Sciences, Wybickiego 7, 31-261 Krakow, Poland \\ Correspondence should be addressed to Zenon Pilecki; pilecki@min-pan.krakow.pl
}

Received 10 December 2012; Accepted 18 January 2013

Academic Editor: Jacek Szabelski

Copyright ( $) 2013$ Jaroslaw Slizowski et al. This is an open access article distributed under the Creative Commons Attribution License, which permits unrestricted use, distribution, and reproduction in any medium, provided the original work is properly cited.

\begin{abstract}
The aim of the work was to evaluate the possibilities of excavating a chamber for the Glacier detector, a cylinder with a $74 \mathrm{~m}$ diameter and $38 \mathrm{~m}$ height filled with $100 \mathrm{kT}$ of liquid argon, in the Polkowice-Sieroszowice copper ore mine in the Legnica-Glogow Copper Area (LGOM). Two potential locations were analyzed in a rock salt layer more than $100 \mathrm{~m}$ thick at the depth of $1000 \mathrm{~m}$ and in the anhydrite layer of about $100 \mathrm{~m}$ thick at the depth of $650 \mathrm{~m}$, both lying above the copper ore deposit. The numerical analyses, based on geological, geophysical, and geomechanical research, were carried out to determine the behavior of the system of the chamber and surrounding rock mass. Two creep laws have been adopted for rock salt in the numerical models, Norton and Lubby2. Their coefficients have been adjusted for in situ measurements of the mine galleries convergence starting from the results of laboratory tests. Displacement and stresses of the rock salt in the chamber vicinity are much greater for the Lubby2 law. The displacements indicated at the chamber contour are the reason that the alternative location in the anhydrite layer was more advantageous.
\end{abstract}

\section{Introduction}

The principal goal of the first project phase of Large Apparatus studying Grand Unification and Neutrino Astrophysics (LAGUNA) was to assess the feasibility of a deep underground chamber able to host the giant neutrino detector [1]. The observatory was expected to provide new and unique scientific opportunities and to lead to the discoveries in the field of astroparticle physics. Seven potential locations were being considered in the project: the Boulby potash mine in the UK [2], the Fréjus tunnel in France [3], the Caso tunnel in Italy, the Canfranc tunnel in Spain [4], the Pyhäsalmi metal ore mine in Finland $[5,6]$, the Unirea salt mine in Romania [7], and the Polkowice-Sieroszowice copper ore mine in the Legnica-Glogow Copper Area (LGOM) in Poland $[8,9]$. The location of these sites, with the underlined location of the Polkowice-Sieroszowice copper ore mine, is shown in Figure 1.
This work concerns the location of the detector in the deep underground Polkowice-Sieroszowice copper ore mine in Poland. It was planned to host a Glacier detector, a giant cylinder $74 \mathrm{~m}$ in diameter and 38 meters high filled with $100 \mathrm{kT}$ of liquid argon. The rock salt layer over $100 \mathrm{~m}$ thick at the depth of about $1000 \mathrm{~m}$ lying above the copper deposit was analyzed as a host rock mass in the preliminary study.

The main advantages of this location were the very low level of natural radioactivity background registered there and no water hazard. The rock salt layer seemed to have adequate thickness and homogeneity. Some chambers were already mined; the largest about $100 \mathrm{~m}$ long and $15 \mathrm{~m}$ wide and $15 \mathrm{~m}$ high has been stable for several years and was used a few times for astrophysical experiments.

The favorable location of the Polkowice-Sieroszowice mine near to the A-4 motorway and the airport for transport detector construction and further operation of the laboratory should also be noted. 

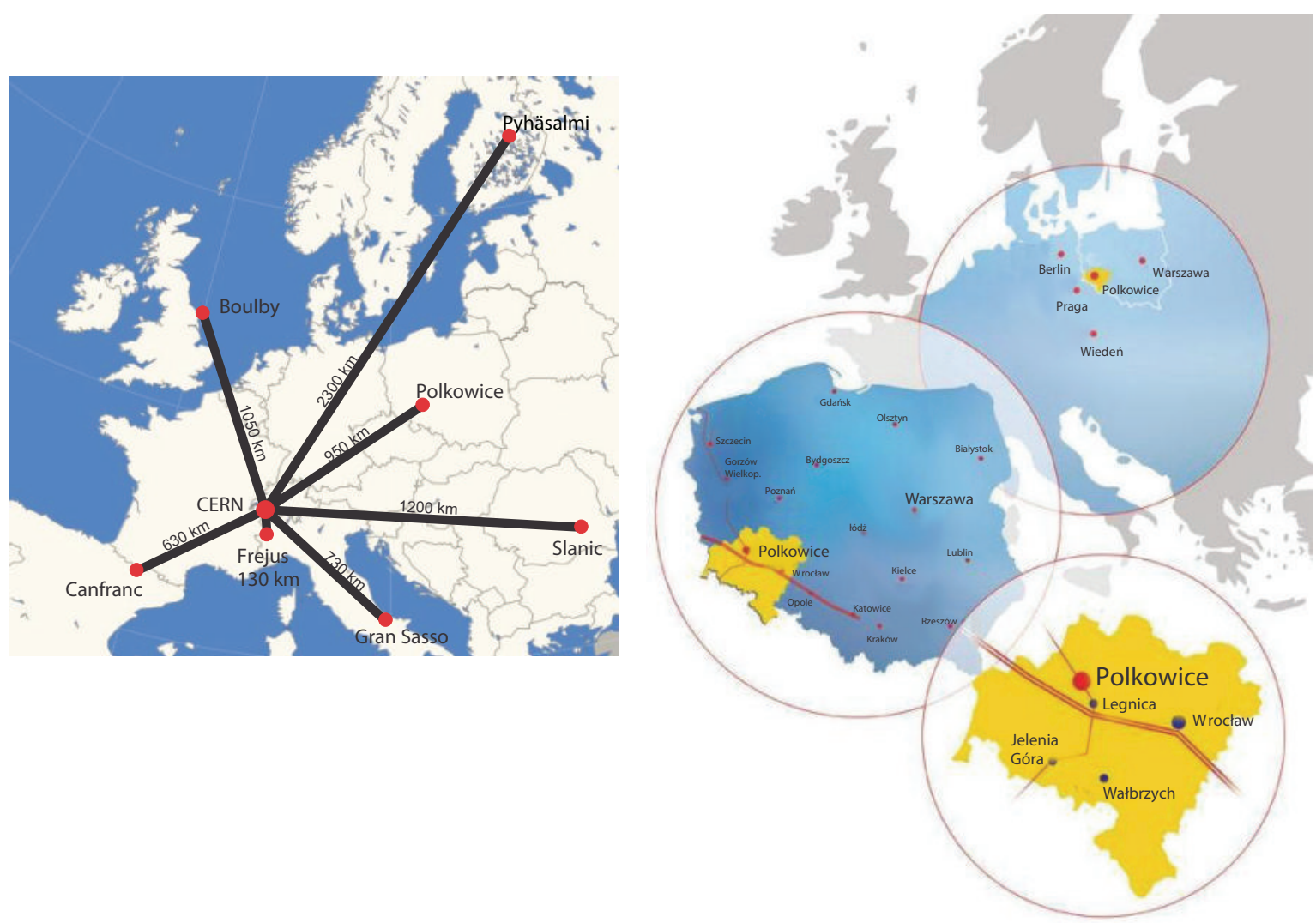

FIGURE 1: The sites considered in the LAGUNA project with the underlined location of the Polkowice-Sieroszowice copper ore mine in Polkowice town, Poland (on the basis of $[1,13]$ ).

A disadvantage of the analyzed location is the depthabout $1000 \mathrm{~m}$-which is considerable, from a geotechnical point of view for a huge excavation in rock salt. Active mine operations, having an impact on the surroundings and also inducing seismicity, can also be problematic. The location of the detector chamber in the anhydrite layer occurring above the rock salt was also taken into account as an alternative to the rock salt layer.

The aim of this work is to present of the preliminary evaluation of the properties and structure of the host rock mass and to consider the possibility of constructing a chamber. This paper presents the results of geological, geophysical, and geomechanical research carried out in the PolkowiceSieroszowice copper ore mine. A large part of these studies was published in the works of Slizowski et al. [10,11].

\section{Geological Conditions}

The field of research lies within the monocline of the Sudetic Foreland [12, 13]. The monocline of the Sudetic Foreland is built of three main rock formations in a broad outline (Figure 2). A rock bed of the monocline, the so-called metamorphic of the interior Oder River, is formed by crystalline and sedimentary rocks from the Proterozoic and the older Paleozoic periods. Permian and Triassic sedimentary systems occur over them. The Cenozoic complex forms the monocline cover-there are deposits from the Paleogene, Neogen, and
Quaternary periods. The individual rock formations occur discordantly, and themselves discordantly, and they are separated by stratigraphic breaks. Permian formations begin with a formation of Red Sandstone. They are built from a conglomerate, sandstone, and shale floor in two similar sequences up to about $450-500 \mathrm{~m}$ in thickness of strata. The copper ore deposit occurs in the floor segments. Permian limestone of the monocline of the Sudetic Foreland is developed in the form of four evaporite cyclothems: Werra, Stassfurt, Leine, and Aller. The most developed cyclothem, Werra, begins with cupriferous shale deposits. The carbonate deposits, including carbonate of limes and dolomite rocks from 5 to $70 \mathrm{~m}$ in depth of strata, are lying above cupriferous shale. Dolomite rocks which often contain copper sulfide predominate in the southern part of the monocline. Lower anhydrites from about several dozens up to over hundred meters in thickness of strata are lying over the carbonate deposits. The oldest, bright-grey, coarse- and medium-crystalline rock salt occurs on the lower anhydrites in the northeastern part of the monocline of the Sudetic Foreland. Rock salt beds stretch from several dozens up to a few hundred meters in depth of strata, and it can be observed that the general tendency of this increase is in a northerly direction. A rock salt seat occurs at a depth of 631 up to 1229 meters and a roof at a depth of 628 up to 1099 meters.

The thickness of strata of the rock salt deposit all over the mining area of the Polkowice-Sieroszowice mine is from 

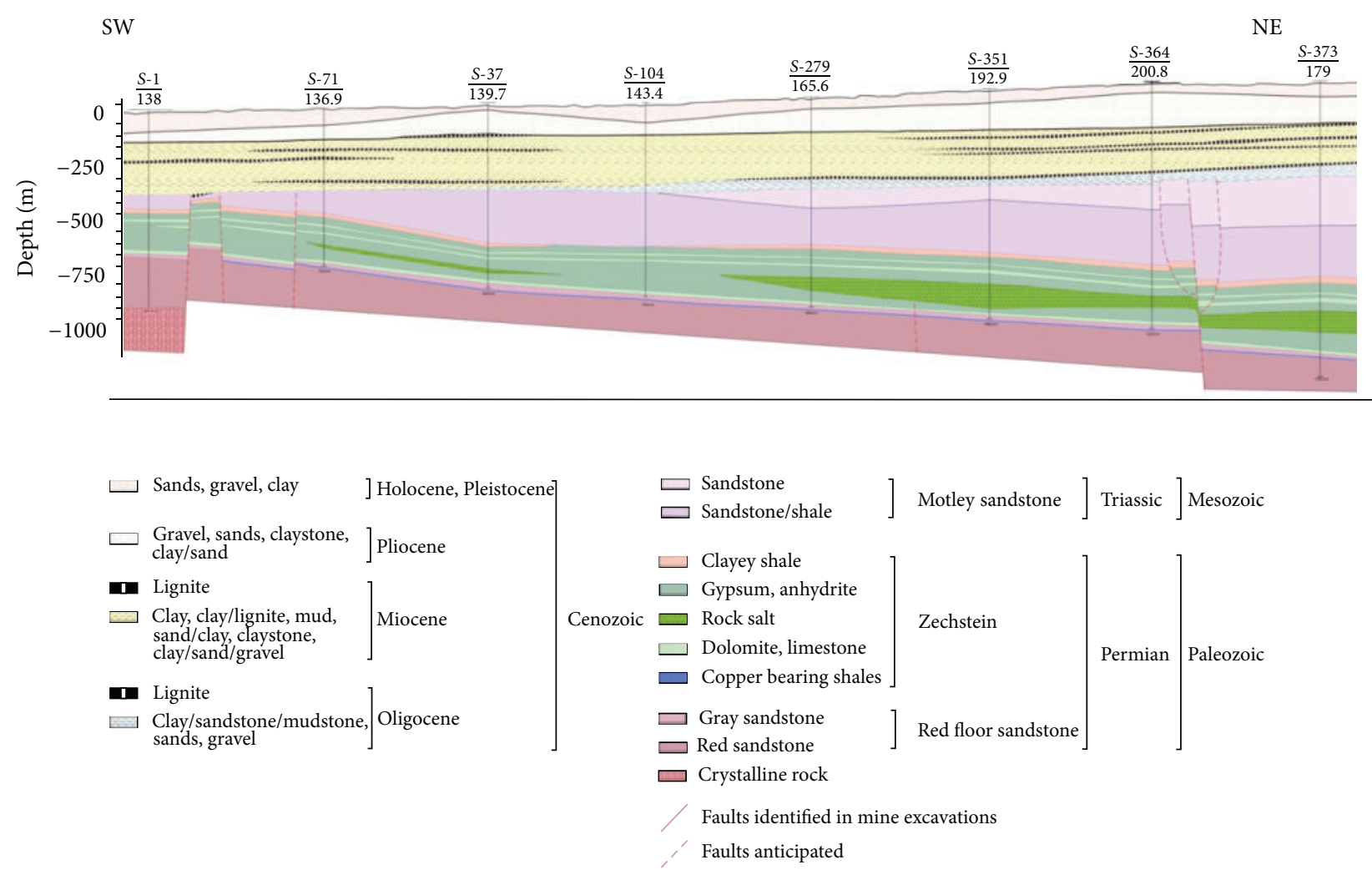

FIGURE 2: The cross-section of the southern part of the mining areas for the Legnica-Glogow Copper Area (LGOM) [13].

0 to 186 meters -65 meters on average. It is distinguished by a lot of salt varieties in the rock salt bed which show different contents of $\mathrm{NaCl}$. The coarse- and high-crystalline variety is characterized by the greatest content of $\mathrm{NaCl}$. A medium content of $\mathrm{NaCl}$ is determined at a level of $98.2 \%$. Upper anhydrites, in which end up deposits of cyclothem Werra, occur above the rock salt. The depth of strata of the upper anhydrites does not exceed hundred meters.

The thickness of strata differentiation of evaporites is closely bound up with weathering processes, as evidenced by clay-anhydrite and gypsum breccia layers often having heavy depths of strata as well. The general dip of beds on the monocline of the Sudetic Foreland is $2-5^{\circ}$ in a northeast direction. The locally occurring larger declines of up to $25^{\circ}$ are connected with roof elevation angle slopes of sandstone deposits.

The biggest influence on the structural composition of the monocline area of the Sudetic Foreland was exerted by tectonic movements of the Laramie phase between the Cretaceous and Paleogene. Earlier earth movements also had an essential meaning for the tectonics of the monocline. At the turn of Keuper, the complex of limestone and schist, had arisen the oldest fault system in a NW-SE direction, together with accompanying fissures in the old-Kymeric phase. The fault system in the NW-SE direction creates blocks dropping in an NE direction which are built of red sandstone deposits, Permian limestone, and the Bunter. They are characterized compressively. The remaining groups of faults on a longitudinal and latitudinal course are less important.
The faults are usually grouped into tectonic zones of irregular course, from several dozens of meters up to above one kilometer in width to over ten and twenty kilometers in length. The faults running in parallel create systems of horsts and rift valleys. The length of individual faults ranges from 200 to 1000 meters. The average gradient of fault surface varies from 71 to $75^{\circ}$, and thrusts are generally small; about $60 \%$ of them do not exceed one meter.

The block tectonics exerted influence on the present layer structure of the rock salt. The fault system in the rock salt layer floor does not diverge from the system determined at the Permian limestone level. The faults occur in an NW-SE and $\mathrm{W}$-E direction. A part of them goes out from the bed on account of the salt's plastic properties. The floor part of the rock salt bed is displaced to a smaller degree, with larger faults in this connection, but, in contact with the upper anhydrites, minor faults can occur with a limited range.

Two main water-bearing complexes may be singled out on the analyzed monocline area of Sudetic Foreland:

(i) the Cenozoic-comprised of loose deposits of the Neogene and Paleogene periods with intergranular water circulation,

(ii) the Triassic-Permian-occurring in cohesive, porous and fissured-cavernous rocks of the Bunter, Permian limestone as well as Red Sandstone with mainly fissured and porous-fissured water circulation. 
These complexes differ markedly in lithological development, the way of formation and chemistry of water resources, and thus hydrogeological parameters.

\section{Rock and Rock Mass Properties}

3.1. Geophysical Examinations. The rock salt layer is slightly fractured and faulted. A different geomechanical situation occurs in the case of the adjoining anhydrite and dolomite layers which are fractured on the whole and may be waterlogged in a diversified manner. The least preferred conditions are to be expected in the contact zones between these layers. Surveys of seismic direct P-wave velocity changes and fissuring degree in rock mass were made by applying seismic and georadar profiling with the use of a shielded $100 \mathrm{MHz}$ antenna [14]. Seismic surveys were also aimed at determining the static deformation modules for the separate layers by Barton's empirical formula [15].

Investigations were made in the side walls of excavations carried out at different intervals: almost twenty years ago (Ps3 gallery) for the contact zone of the rock salt and anhydrite, as well as in a gallery "freshly" prepared by using the heading machine in the contact zone of anhydrite and dolomite (Ps-1 gallery). The underground workings were located at a depth of about 1000 meters. Georadar profiling carried out in the Ps-3 gallery showed a fracturing structure of anhydrite and rock salt layers (Figure 3 ). The discontinuity and lithological borders were noticeable on an echogram. Intense fracturing in a segment of several meters in the contact zone of anhydrite and rock salt layers was recorded. Damage along the side wall was observed, in particular occurrence in a segment of anhydrite. Breccia zones occurred locally in the anhydrite. There might be lenses of postsedimentary rock salt. Larger discontinuities were not observed outside the side wall zone. Reconnaissance further away from the side wall revealed probably the lithological boundary between the anhydrite and rock salt. The degree of fracturing of rock salt is significantly lower in comparison to anhydrite.

Seismic studies have shown significant differences in Pwave velocity and static deformation modulus in the analyzed rock layers (Table 1). The most advantageous elastic properties are stated for the anhydrite and dolomite layers. The seismic P-wave velocities are decidedly larger in "freshly" made underground workings as a result of a shorter period of weathering and rheological processes. The elastic properties of the strongly disturbed layer of anhydrite are similar to the properties of the rock salt layer.

\subsection{Laboratory Tests}

3.2.1. Elastic Properties. In the case of rocks with high elasticity, amongst which anhydrites are numbered, a determination of elasticity parameters is not complicated. The values of Young's modulus and Poisson ratio are presented in Table 2. It should be noted that Young's modulus values have a considerably smaller scatter in the case of a specific sampling location.
A more complex situation occurs in the case of rock salt on account of its high plasticity. The fraction of reversible elastic strains in total strain is small. The characteristics throughout its range are nonlinear, mostly due to nonlinearity of plastic strengthening. Young's modulus was determined at different states $\left(E_{0}, E_{1}, E_{2}, E_{3}\right)$. The stress $\left(\sigma_{1}\right)$ - strain $\left(\varepsilon_{1}\right)$ curves are shown in Figure 4.

Experiences with the numerical calculations, however, show that the parameter values of elasticity are of secondary importance, not significantly affecting the state of deformations and stresses of rock mass surrounded by underground workings in the rock salt [16]. The rheological properties are more important.

3.2.2. The Rheological Properties of Rock Salt. Analysis of the rheological properties of rock salt in cyclothem Werra from the Polkowice-Sieroszowice copper ore mine is based on two series of experiments described in [10]. The investigations in 1991 lasted 175 days in the case of uniaxial creep tests, while they lasted 147 days in the case of triaxial creep tests, and were made only at room temperature. The duration of all the tests in 2001 amounted to 115 days, in addition to which the temperature was raised to $40^{\circ} \mathrm{C}$ as regards the samples in the triaxial stress state, corresponding to the temperature of the rocks in the Polkowice-Sieroszowice mine at a depth of about 1000 meters.

Figure 5 shows an example of the results of triaxial creep test for two values of effective stresses, while Figure 6 presents the creep test results of two samples at the changed temperature as well as effective stress.

There was a clear difference in the testing of creep rate of salt samples due to the varying thickness of the grains, which may even be a factor of ten. The creep law parameters that can be obtained in these tests may not be precise. However, the research results indicate that the rock salt in the cyclothem Werra from the Polkowice-Sieroszowice mine is very fast creeping.

Figure 7 shows the creep rates of salt samples from the Polkowice-Sieroszowice mine obtained at room temperature. Two lines representing creep laws known in the literature as BGRa and BGRb $[17,18]$ are presented for reference purposes.

3.2.3. Strength Properties. Strength tests were performed for various samples of different rock salt of difference grain thickness, as well as for anhydrite from cyclothem Werra (Table 3). In the case of rock salts, the results were obtained by Slizowski et al. [10] based on uniaxial and triaxial compression tests, tension (direct and Brazilian methods), and shear test at different angles between the direction of the compressive force and the shear plane. As regards the anhydrite, the tests were conducted by KGHM Cuprum, based on uniaxial compression and tension using the direct method [10].

In rock salt, there is a visible dependence on the parameters of the orientation of the sample in relation to the bedding, especially evident in the uniaxial compression tests. In general it was found that the uniaxial strength changes of rock salt are mainly due to the differentiation of its grains. 
TABle 1: Seismic properties of rock mass in two galleries: Ps-1 and Ps-3 [13].

\begin{tabular}{|c|c|c|c|c|}
\hline \multirow{2}{*}{ Type of rock mas/Ps-1 and Ps-3 } & \multicolumn{2}{|c|}{$P$-wave velocity $(\mathrm{m} / \mathrm{s})$} & \multicolumn{2}{|c|}{ Deformation modulus* $\left.{ }^{*} \mathrm{GPa}\right)$} \\
\hline & Range & Mean & Range & Mean \\
\hline \multicolumn{5}{|l|}{ Rock salt layer } \\
\hline Ps-1 & - & - & - & - \\
\hline Ps-3 & $4400-5150$ & 4817 & $8.4-18.0$ & 13.9 \\
\hline \multicolumn{5}{|l|}{ Anhydrite layer } \\
\hline Ps-1 & $5950-6700$ & 6440 & $50.4-119.4$ & 88.6 \\
\hline Ps-3 & $5000-5480$ & 5310 & $16.9-29.3$ & 24.1 \\
\hline \multicolumn{5}{|l|}{ Dolomite layer } \\
\hline Ps-1 & $5900-6350$ & 6260 & $47.6-70.8$ & 72.0 \\
\hline Ps-3 & - & - & - & - \\
\hline
\end{tabular}

*Static modulus by Barton's empirical formula [15].

TABLE 2: Elastic parameters obtained for rock salt and anhydrite laboratory tests.

\begin{tabular}{lcccc}
\hline Parameter & Rock salt & & \multicolumn{2}{c}{ Anhydrite } \\
& Range & Mean & Range & $52.4-68.2$ \\
Young's modulus $(\mathrm{GPa})$ & $0.5-30.0$ & 8.0 & $0.22-0.26$ & \\
Poisson ratio $(-)$ & $0.15-0.30$ & 0.20 & 0.25 \\
\hline
\end{tabular}

Geotechnical research of the rock salt mechanical properties showed that different parts of the deposit differ strongly with strength parameters and creep rate, in spite of being of the same origin-oldest halite Nal belonging to cyclothem Werra. Values of uniaxial compression strength were higher (25.3-38.8 MPa) for samples of fine-grained impure salt, cut perpendicularly to the bedding of the deposit than for samples of coarse-grain pure salt, and cut parallel to the bedding (20.1-29.7 MPa).

The strength of anhydrite obtained under laboratory conditions varies and decreases in the presence of interlayers.

3.3. Determination of Rock Mass Mechanical Properties. The properties of the rock salt layer are slightly different from the properties of rock salt samples determined under laboratory conditions. Undoubtedly, the unfavorable elements in the saline layers are the fractures and faults occurring to a small extent, mainly in the contact zone. However, the mechanical properties of the anhydrite layer differ significantly from the parameters determined under laboratory conditions. A preliminary observation of the rock mass in the mine, as well as results of conducted geophysical surveys, clearly shows the distinct fractures of the anhydrite layers, the presence of weak zones in the form of breccia, and relatively high fissuring in the areas of contact with adjoining rocks (Figure 12).

An RQD index as well as other parameters was measured for purposes of $\mathrm{RMR}_{89}$ rating calculations (Bieniawski 1989) in Ps-1 gallery. The rock mass parameters were calculated by applying the RocLab program developed by Hoek (Table 4). The parameters of strata adjacent to a layer of rock salt are clearly less favorable than those obtained under laboratory conditions presented in Tables 2 and 3.

The parameters collated in Table 4 were accepted for numerical calculations. The parameters of the rock salt layer were not subjected to reduction as shown in Tables 2 and 3.
One study that was carried out was the rock temperature on the side walls as well as at three points into the rock mass, the furthest of which was at 2.7 meters deep in a gallery and operating chamber. The achieved results showed that the temperature at all points was almost the same and averaged $35.5^{\circ} \mathrm{C}$.

\section{Determination of Creep Law Coefficients}

The calculations were performed using two creep lawsNorton and Lubby2 [19]. Norton law describing the stationary creep is as follows:

$$
\dot{\varepsilon}_{e f}=A e^{-(\mathrm{Q} / R T)} \sigma_{e f}{ }^{n},
$$

where $Q$-activation energy, $R-8,3144 \mathrm{~J} \cdot \mathrm{mol}^{-1} \mathrm{~K}^{-1}$-gas constant, $T$-absolute temperature $\left[{ }^{\circ} \mathrm{K}\right], A, n$-empirical constants, commonly known Maxwell creep law may be regarded as a special case of Norton law with assumptions $n=1$ and

$$
\eta(T)=\frac{e^{Q / R T}}{A} .
$$

The coefficients $A, n$ and the quotient value $Q / R$ are determined empirically on the basis of creep tests performed at different temperatures and stresses.

Lubby2 creep law, being a generalization of Burger's rheological model, describes both stationary and primary creep. In other words, Lubby 2 creep law describes the formula analogous to Burger's model, in which the coefficients are not 
TABLE 3: Strength parameters of rock salt and anhydrite with rock salt impurities from the Polkowice-Sieroszowice mine [10].

\begin{tabular}{lccc}
\hline Parameter & Rock salt & Anhydrite & Anhydrite with impurities \\
\hline$R_{c}(\mathrm{MPa})$ & $25.3-38.8 / 20.1-29.7^{*}$ & 92.3 & 63.84 \\
$R_{c t}(\mathrm{MPa})$ & $57.2 / 79.47 / 94.2 /^{* *}$ & - & - \\
$R_{r}(\mathrm{MPa})$ & $0.25 / 1.0^{*}$ & 4.9 & 3.8 \\
$R_{s}(\mathrm{MPa})$ & $2.9 / 2.3^{*}$ & - & - \\
\hline
\end{tabular}

${ }^{*}$ Perpendicular/parallel to the bedding; ${ }^{* *} \sigma_{3}=2 \mathrm{MPa} / \sigma_{3}=5 \mathrm{MPa} / \sigma_{3}=10 ; R_{c}$ : uniaxial compressive strength; $R_{c t}$ : triaxial compressive strength; $R_{r}$ : uniaxial tension strength; $R_{s}$ : uniaxial shear strength.

TABLE 4: Calculation values of strength and elastic parameters for anhydrite and neighboring layers used for numerical calculations [13].

\begin{tabular}{|c|c|c|c|c|c|c|}
\hline Rock mass type & $R_{c}(\mathrm{MPa})$ & $R_{r}(\mathrm{MPa})$ & $c(\mathrm{MPa})$ & $\varphi(\mathrm{deg})$ & $E(\mathrm{MPa})$ & $v(-)$ \\
\hline Sandstone & 6.43 & 0.06 & 2.1 & 30.1 & 44.7 & 0.26 \\
\hline Shale & 1.47 & 0.003 & 0.6 & 24.7 & 1.3 & 0.29 \\
\hline Anhydrite upper & 16.51 & 0.20 & 4.2 & 34.3 & 11.3 & 0.24 \\
\hline Anhydrite lower & 27.55 & 0.36 & 6.3 & 37.6 & 18.3 & 0.23 \\
\hline Dolomite, limestone & 105.0 & 1.49 & 20.0 & 53.3 & 67.5 & 0.18 \\
\hline
\end{tabular}

$R_{c}$ : uniaxial compressive strength; $R_{r}$ : uniaxial tension strength; $c$ : cohesion; $\varphi$ : internal friction angle; $E$ : Young's modulus; $v$ : Poisson ratio.

constant but are exponential functions of effective stress or effective stress and temperature (stationary creep):

$$
\begin{gathered}
\dot{\varepsilon}_{e f}\left(\varepsilon_{e f}^{c r}\right)=\left[\frac{1}{3 \eta_{K}\left(\sigma_{e f}\right)}\left(1-\frac{\varepsilon_{e f}^{c r}}{\sigma_{e f}} G_{K}\left(\sigma_{e f}\right)\right)\right. \\
\left.+\frac{1}{3 \eta_{M}\left(\sigma_{e f}, T\right)}\right] \sigma_{e f}, \\
G_{K}\left(\sigma_{e f}\right)=G_{0} e^{k_{1} \sigma_{e f}}, \quad \eta_{K}\left(\sigma_{e f}\right)=\eta_{0} e^{k_{2} \sigma_{e f}}, \\
\eta_{M}\left(\sigma_{e f}, T\right)=\eta_{0} e^{m \sigma_{e f}} e^{l T},
\end{gathered}
$$

where $G_{K}$-Kelvin shear modulus, $\eta_{K}$-Kelvin viscosity, $\eta_{M}$-Maxwell viscosity, $k_{1}, k_{2}, m, l$-empirical constants.

A significant feature of the tested rock salt is the strong influence of temperature on the creep rate. It was impossible to derive reliable coefficients of creep laws from dispersed values of laboratory creep rate. Fortunately, convergence measurements performed in the mine gallery could be used to validate the creep laws. The gallery was about $5.0 \mathrm{~m}$ high and $6.5 \mathrm{~m}$ wide. Horizontal displacement benchmarks were placed on the gallery wall $1.5 \mathrm{~m}$ above the bottom, opposite to each other; vertical displacement benchmarks were placed at the center of the gallery roof and bottom. Three benchmarks were placed at each location-stabilized at $0.2 \mathrm{~m}, 2.5 \mathrm{~m}$, and $5.0 \mathrm{~m}$ inside the rock salt.

Finally, two creep laws have been adopted for the numerical models-Norton and Lubby2, whose coefficients have been validated using in situ measurements of the mine gallery side wall displacements after several modelings with different coefficients from the range given by laboratory tests.

It was found that both laws give similar qualitative results (Figure 8), but considering the horizontal displacements, better results were obtained for Lubby2, as opposed to vertical displacements, where better results were obtainedfor Norton's law. It is not surprising that, in general, slightly better results were given by Lubby2, because it includes both the primary creeping and stationary creeping.

Finally, the adopted coefficients were as follows:

(i) Norton law: $n=5 ; A=0,010772 \mathrm{MPa}^{-5} ; \mathrm{Q} / \mathrm{R}=$ $5750 \mathrm{~K}$,

(ii) Lubby2 law: $G_{K}=8091 \mathrm{MPa} ; k_{1}=-0,150 \mathrm{MPa}^{-1}$; $\eta_{K}=89633 \mathrm{MPa} \cdot \mathrm{d} ; k_{2}=-0,150 \mathrm{MPa}^{-1} ; \eta_{M}=$ $24075000 \mathrm{MPa} \cdot \mathrm{d}($ at $313 \mathrm{~K}) ; m=-0.30 \mathrm{MPa}^{-1}$.

\section{Stability Assessment}

The section refers to the most interesting results from the perspective of stability assessment. Two potential locations for the Glacier detector chamber and its dimensions are schematically presented in Figure 9. Axisymmetrical models of FLAC2D and FLAC3D were used to simulate the behavior of rock formation around the detector chamber. Excavation support by bolting was not taken into account in the preliminary calculations presented in the following section.

5.1. Rock Salt Layer. The rock salt layer of the Werra cyclothem in the Polkowice-Sieroszowice mine is situated between two layers of anhydrite (Figure 9), a rock mass with a high value of Young's modulus. Therefore, it could be expected that the location of the chamber near the layers of anhydrite significantly reduces the value of the displacement. Numerical simulations were carried out for several models of different geological configurations. Two of them are compared in Table 5:

(i) chamber in very thick salt layer (no anhydrite layers in the chamber vicinity),

(ii) chamber in salt layer between two layers of anhydrite $15 \mathrm{~m}$ below the chamber floor and $30 \mathrm{~m}$ above the chamber roof. 
TABle 5: Maximal horizontal displacement of chamber wall and vertical displacement of the chamber bottom and roof [10].

\begin{tabular}{lcccc}
\hline \multirow{2}{*}{ Model } & Creep law & & Maximal displacement (m) \\
& & Wall & Bottom & Roof \\
\hline \multirow{2}{*}{ Rock salt } & Norton $n=5$ & 2.42 & 3.11 & 2.75 \\
& Lubby2 & 3.93 & 5.06 & 4.46 \\
\hline \multirow{2}{*}{ Rock salt with anhydrite } & Norton $n=5$ & 1.34 & 0.16 & 0.26 \\
\hline
\end{tabular}

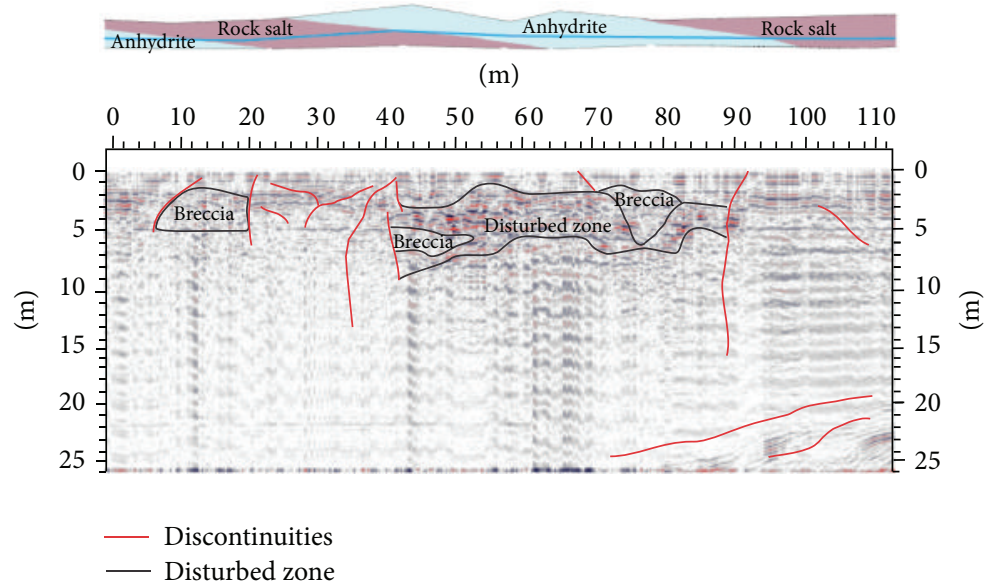

FIGURE 3: Georadar cross-section through the contact zone between rock salt and anhydrite layer along the side wall of the Ps-3 gallery [10].

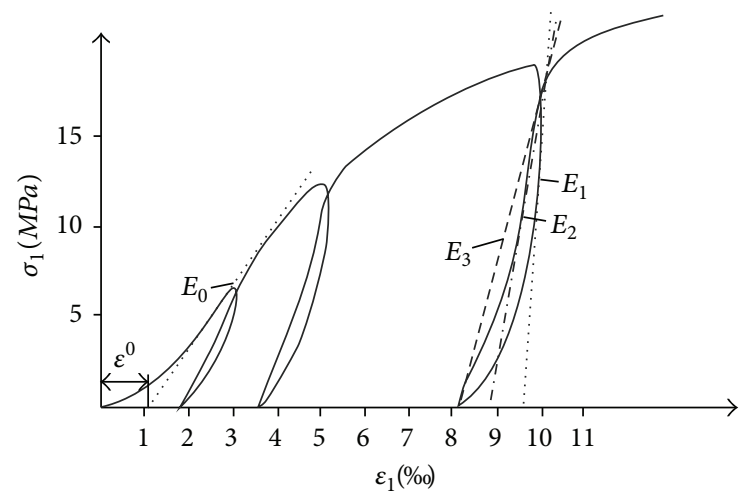

Figure 4: Typical stress-strain characteristics of rock salt in a cyclic uniaxial compression test [10].

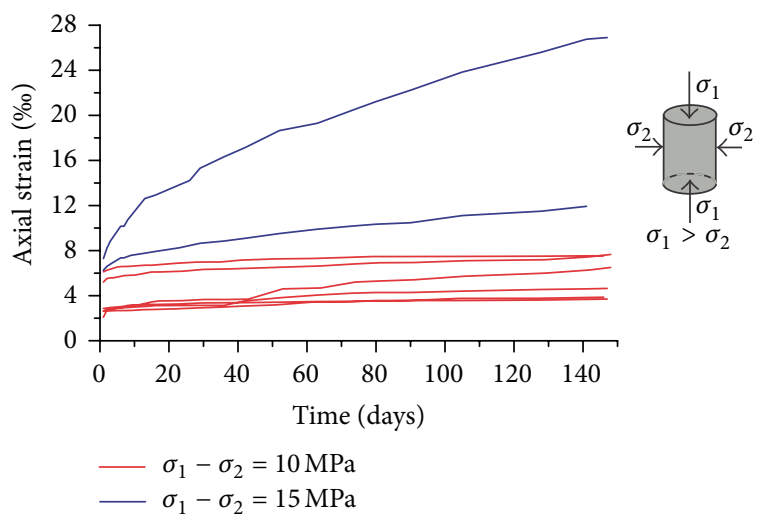

FIGURE 5: Selected triaxial creep tests results obtained for rock salt samples from the Polkowice-Sieroszowice copper ore mine [10].

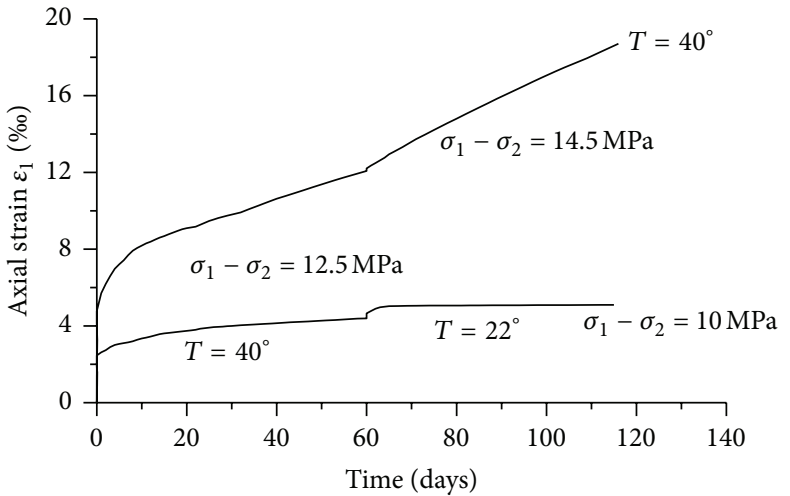

FIgURE 6: Triaxial creep of rock salt samples at different temperatures $(T)$ and stress conditions $\left(\sigma_{1}-\sigma_{2}\right)$ from the PolkowiceSieroszowice copper ore mine [10].

As can be seen from Table 5, the vicinity of anhydrite layers strongly reduces the vertical displacements of the floor, while the horizontal displacements of the wall are reduced by nearly $50 \%$. Such a result could be regarded as beneficial if the contact zones of salt and anhydrite rocks were not disturbed.

However, based on observations of the mine's workings and results of geophysical surveys, it has been noted that a strongly disturbed zone occurs at the border between the salt and anhydrite layers which has a thickness of several meters. Therefore, the chamber cannot be located in such a close proximity to the layers of anhydrite. On the other hand, the influence of anhydrite layers decreases with the distance from these layers. For example, in the case of the model where the anhydrite layers occurred $70 \mathrm{~m}$ below the bottom and 


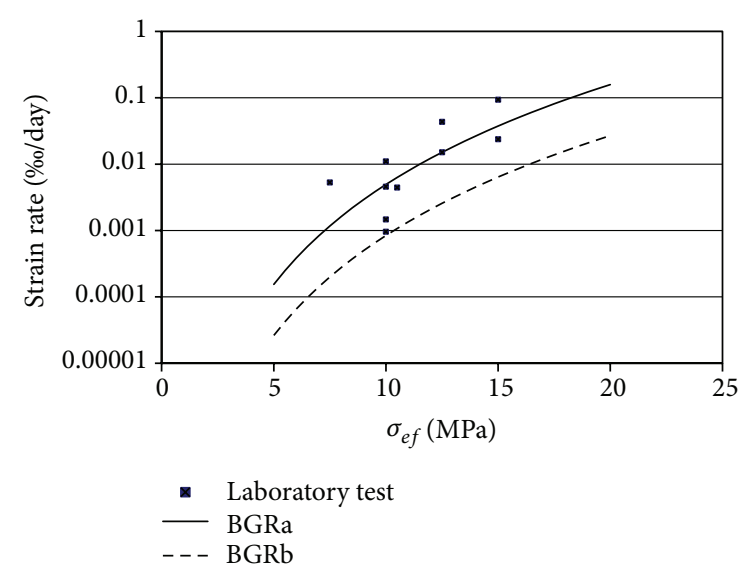

FIGURE 7: Comparison of stationary creep rate of rock salt samples (tests done in 1991-mean values, in 2001-all the values) with BGRa and BGRb [10].

$60 \mathrm{~m}$ above the roof, the values of vertical and horizontal displacements were lower by only a few percent compared to the model with no anhydrite layer.

The stress-strain state in the rock mass for the demanded time of laboratory operation (approximately $40-50$ years) is highly dependent on the applied creep law. The difference in the values of displacements obtained using the Norton and Lubby 2 creep laws is an important feature of the results and can be seen in Table 5 .

The next aspect analyzed was the value of the stress in the rock salt surrounding the chamber. The greatest values of effective stress-and consequently the failure factor (the inverse of the safety factor)-are observed at the chamber walls. The following two strength criterions were used to assess the rock mass stability:

(i) Burzynski, an optimistic criterion [16] where intermediate principal stress has no influence on the strength, and the failure factor is given by relation of Burzynski stress to uniaxial compression strength; a value of 0.3 should guarantee long-term stability,

(ii) Hunsche [17], a conservative criterion describing the strength of the weakest salt, and the failure factor is given by relation of effective stress to maximum allowable value according to Hunsche; a value of 0.5 should guarantee long-term stability.

The corresponding failure factor distributions along the chamber wall are shown in Figure 10. The high values of the failure factor obtained with the Hunsche criterion indicate that the presence of the weakest salt in the chamber vicinity may lead to rock spalling at the chamber walls. The results led to the conclusion that chamber stability can be achieved only in the case of favorable geological conditions at the chamber site.

Very probably, favorable conditions could be the reason for the good stability of the large chamber made in the mine several years ago. Partially, these conditions may also be associated with a decrease in the temperature by $5-7^{\circ} \mathrm{C}$ in the rock mass due to water drainage and ventilation. Aside from the favorable geological conditions, the site must be distant from the zone disturbed by the copper ore mining operations.

Numerical calculations were also performed, adopting much less favorable properties of anhydrite rock mass in comparison with the results obtained from laboratory tests of rock samples. Despite such conservative assumptions, the calculations showed that situating the chamber in the layer of anhydrite is acceptable from the geomechanical point of view. The area of the ventilation shaft of the PolkowiceSieroszowice mine was selected as a most promising location. Nevertheless, confirmation of this location requires excavation of access galleries and detailed geophysical surveys.

5.2. Anhydrite Layer. The sufficient depth for proper functioning of the Glacier detector is 600 meters of water equivalent which, under local conditions for the PolkowiceSieroszowice mine, corresponds to depth of $250-300 \mathrm{~m}$. As a consequence, an anhydrite layer occurring in the mine at a depth of $650 \mathrm{~m}$ was considered as an alternative location.

The main advantages of this location are the high strength of the anhydrite rock mass and the shallower depth allowing the chamber to be placed at $650 \mathrm{~m}$. Disadvantages of such a location are the widely varying properties of the anhydrite rock mass due to tectonic engagement and water hazard.

Numerical simulations were performed using the calculation values for rock parameters given in Table 4. Several models were considered which differed in primary stress states in the rock formation:

(i) model 1: chamber in very thick anhydrite layer (no other rocks taken into account) where primary horizontal stress components are equal to the vertical; that is, $\sigma_{x}=\sigma_{y}=\sigma_{z}=\gamma H$,

(ii) model 2: other rocks underlying and overlying the anhydrite layer taken into account, where primary stresses are in elastic geostatistical formation; that is, $\sigma_{x}=\sigma_{y}=\sigma_{z} v /(1-v)=\gamma H \nu /(1-v)$,

(iii) model 3: other rocks underlying and overlying the anhydrite layer taken into account, where primary horizontal stresses are $36 \%$ higher than the vertical; that is, $\sigma_{x}=\sigma_{y}=1.36 \sigma_{z}=1.36 \gamma \mathrm{H}$,

(iv) model 4: other rocks underlying and overlying the anhydrite layer taken into account, where primary horizontal stresses are different, $40 \%$ of the vertical in the $x$-direction and $80 \%$ of the vertical in the $y$ direction; that is, $\sigma_{x}=0.4 \sigma_{z} ; \sigma_{y}=0.8 \sigma_{z}$,

(v) model 5: other rocks underlying and overlying the anhydrite layer taken into account, where primary horizontal stresses are different, $40 \%$ of the vertical in the $x$-direction and $120 \%$ of the vertical in the $y$ direction; that is, $\sigma_{x}=0.4 \sigma_{z} ; \sigma_{y}=1.2 \sigma_{z}$.

The following two strength criterions were used to assess the rock mass stability:

(i) Burzynski criterion [16] with $R_{c}=27.5 \mathrm{MPa} \alpha=$ $R_{r} / R_{c}=0.05$, 


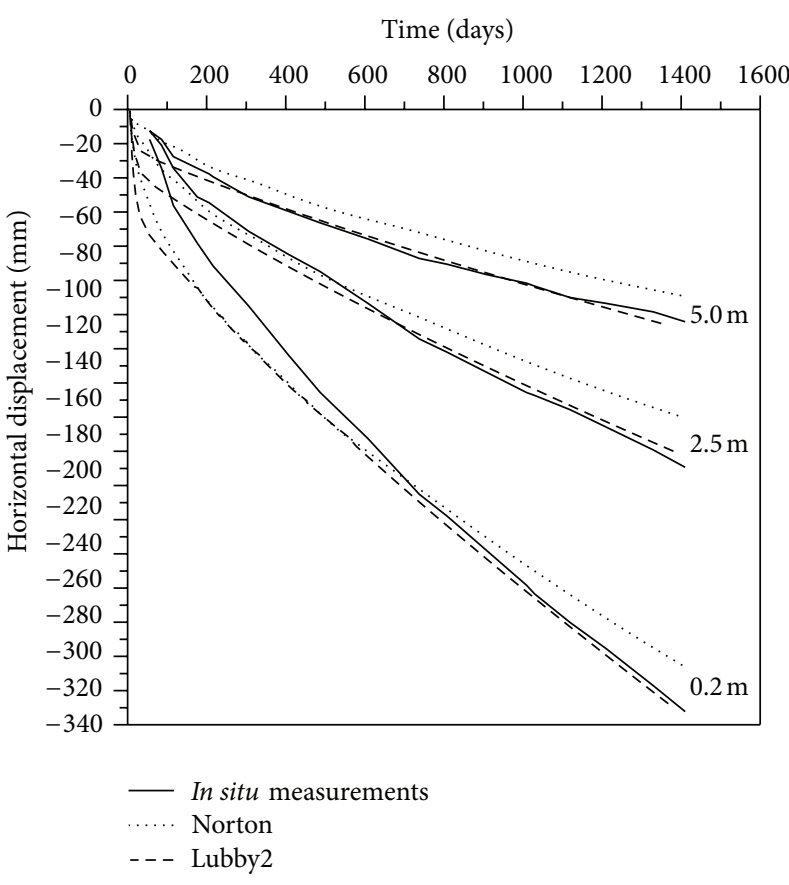

(a)

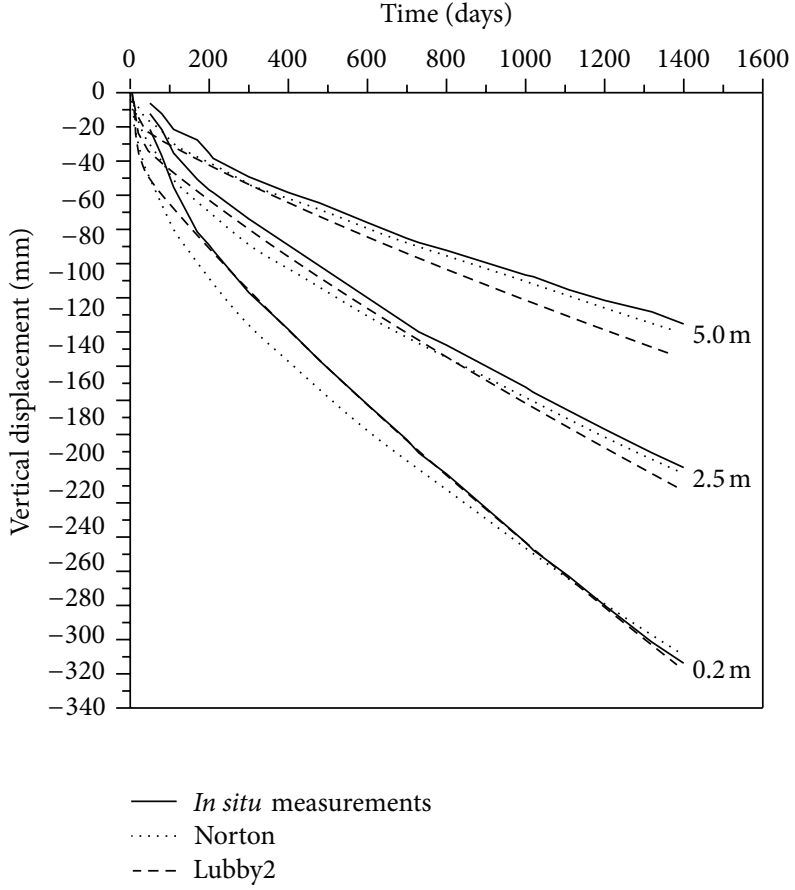

(b)

FIGURE 8: Validation of creep law parameters used in the study; changes of horizontal (a) and vertical (b) displacement versus time in the side wall of the gallery at a $1000 \mathrm{~m}$ depth in the Polkowice-Sieroszowice copper ore mine [11].

(ii) Coulomb-Mohr criterion with $c=6.3 \mathrm{MPa} ; \varphi=38^{\circ}$.

The Coulomb-Mohr criterion leads to a lower failure factor than the Burzynski criterion (Figure 11), but even then, the values do not exceed 0.8 , and according to the accepted criteria, the localization of the Glacier detector chamber in the considered anhydrite layer can be recommended as the most promising.

\section{Resume}

The paper presents geotechnical aspects of the feasibility study for locating the giant astroparticle detector in a very large size chamber in the Polkowice-Sieroszowice mine. Two locations were taken into account, a rock salt layer and an anhydrite layer.

The main advantages of the rock salt location were adequate thickness (more than $100 \mathrm{~m}$ ) at the depth of about $1000 \mathrm{~m}$, no fractures, and no water hazard. Another advantage of this location was the very low level of natural background radioactivity registered there.

The main problem involved in chamber construction in a rock salt layer resulted from the chamber's convergence, that is, the loss of chamber volume over time. The issue was analyzed based on numerical simulation of the rock salt behavior in the chamber's vicinity using two- and threedimensional numerical models. Two creep laws were applied in calculations leading to results which differ significantly. Displacements and effective stresses were much greater for the Lubby 2 than for the Norton creep law. In both cases, the impact range of the chamber was very large due to fast creeping of the rock salt layer, leading to a reduction in effective stress at the chamber contour and an increase at larger distances. The main problem for the detector chamber will be large displacements of the chamber walls and bottom exceeding $3 \mathrm{~m}$ over 50 years. Although the neighboring anhydrite layers can reduce the displacements of salt rock mass at the chamber roof and bottom, the salt-anhydrite contact zone had to be avoided as well. Another disadvantage of a chamber location at a depth of about $1000 \mathrm{~m}$ was the close proximity to the impact zone of active mine operations, also inducing seismicity.

The location in anhydrite is recommended mainly due to two factors-the depth at $650 \mathrm{~m}$ below the surface and the insignificant viscoplastic properties of anhydrite rock at this depth. The numerical calculations indicate that from a geomechanical point of view it is possible to cut a largedimension chamber at a depth $650 \mathrm{~m}$; however, a stability of the chamber can be improved by bolting as shown in Figure 9 or shotcreting.

Parameters of the anhydrite rock in situ are, in fact, much less favorable than those obtained in laboratory tests and are getting worse over time. On the other hand, there is the possibility of the occurrence of diverse tectonic stresses, a phenomenon which is particularly unfavorable when there is a large difference in the values of the two components of horizontal stress.

Summarizing, the location of the chamber in the anhydrite layer is the most promising in geological and mining conditions of the Polkowice-Sieroszowice mine. 


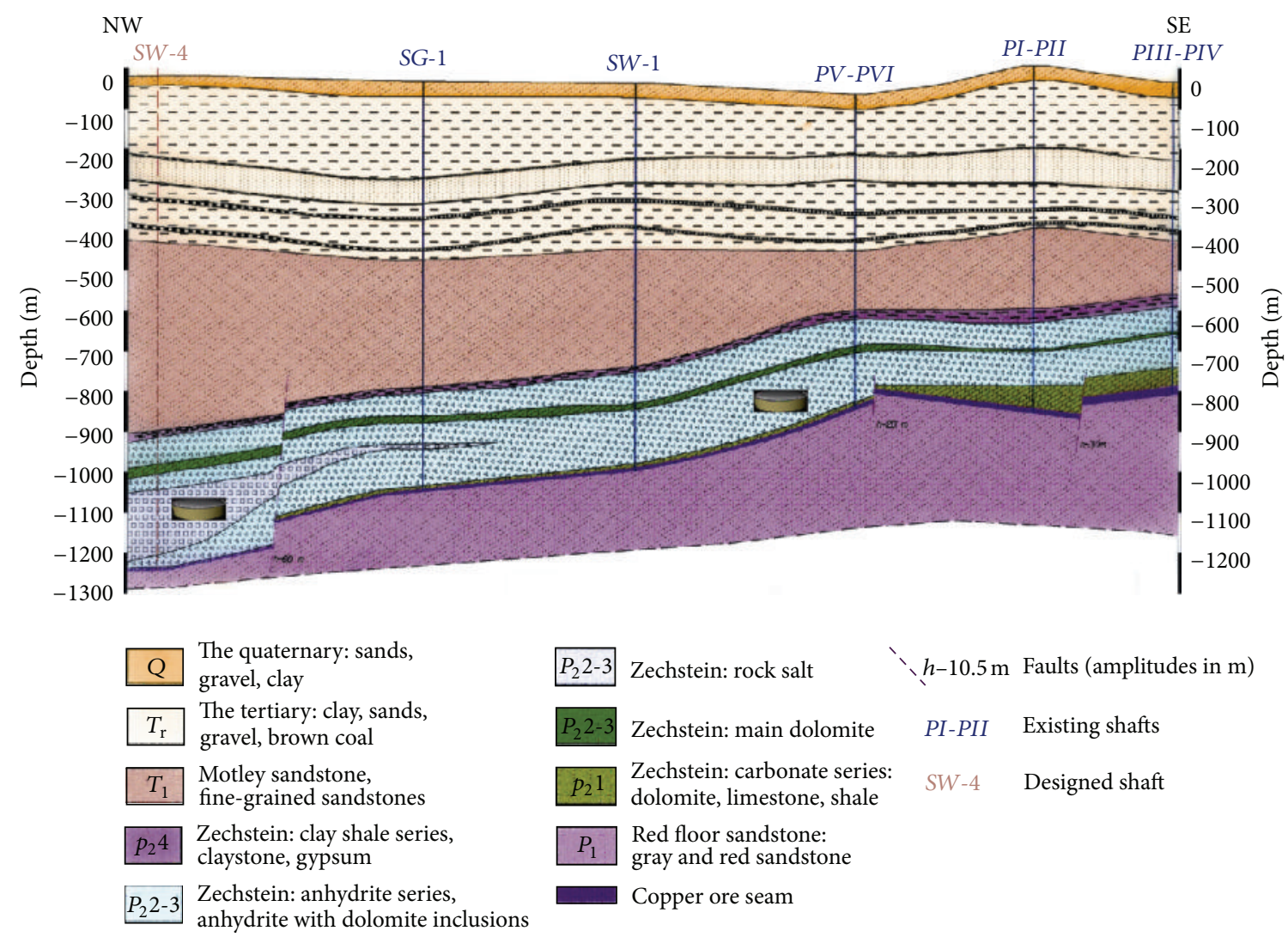

(a)

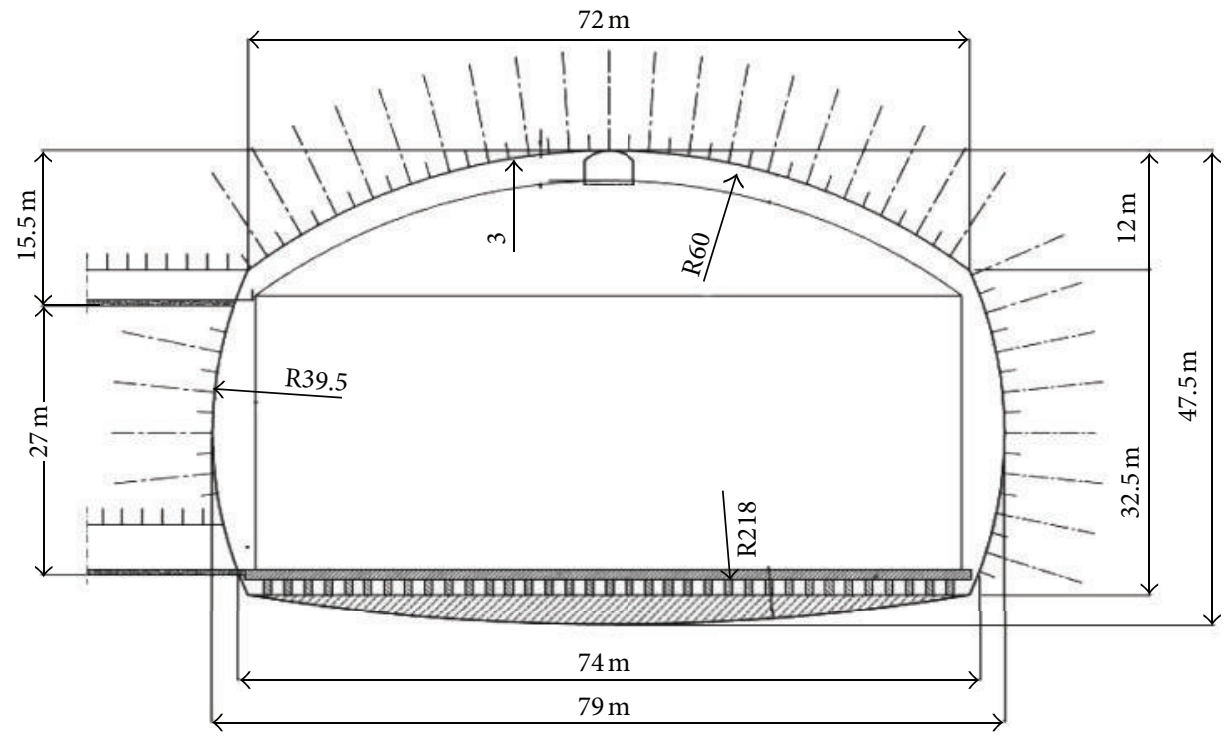

(b)

Figure 9: Proposed detector locations (a) and Glacier chamber dimension in meters (b) used in the numerical modeling on the basis of [13]. 


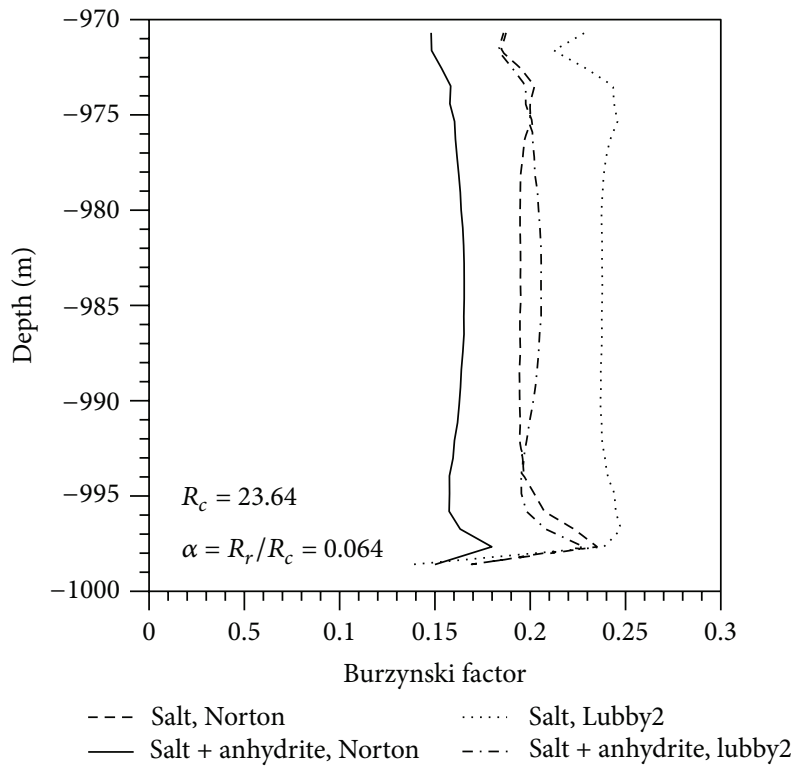

(a)

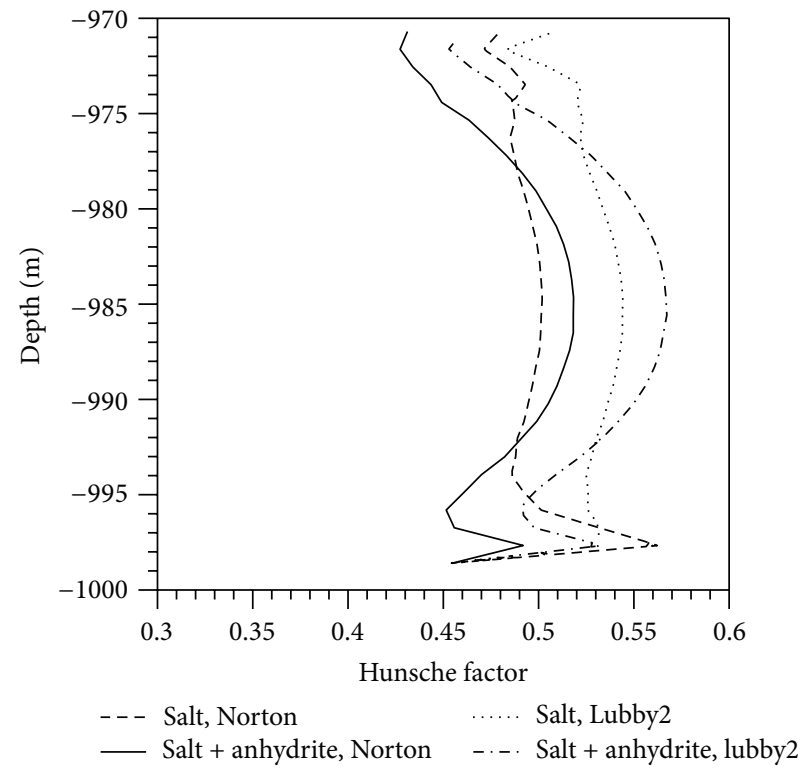

(b)

FIGURE 10: Failure factor according to Burzynski criterion (a) and to Hunsche criterion (b) along the chamber wall for the detector chamber in rock salt [11].

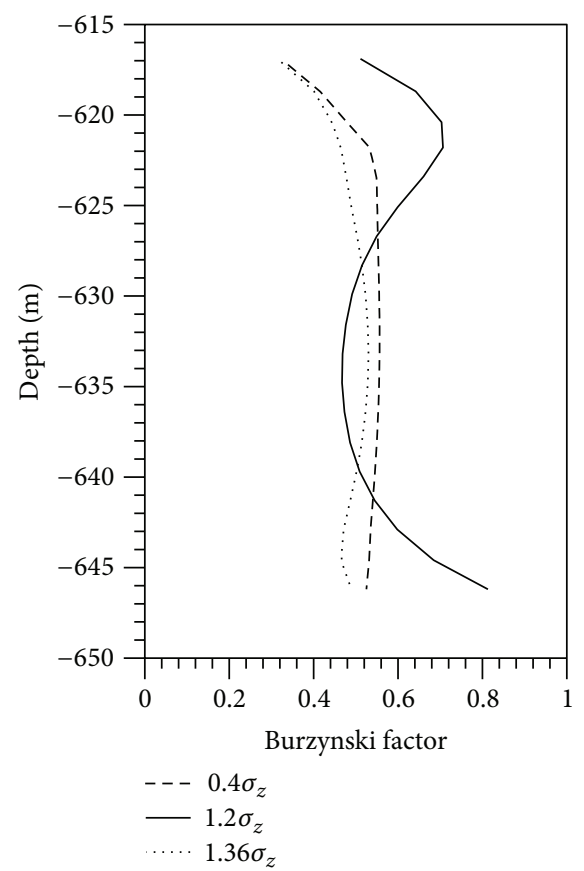

(a)

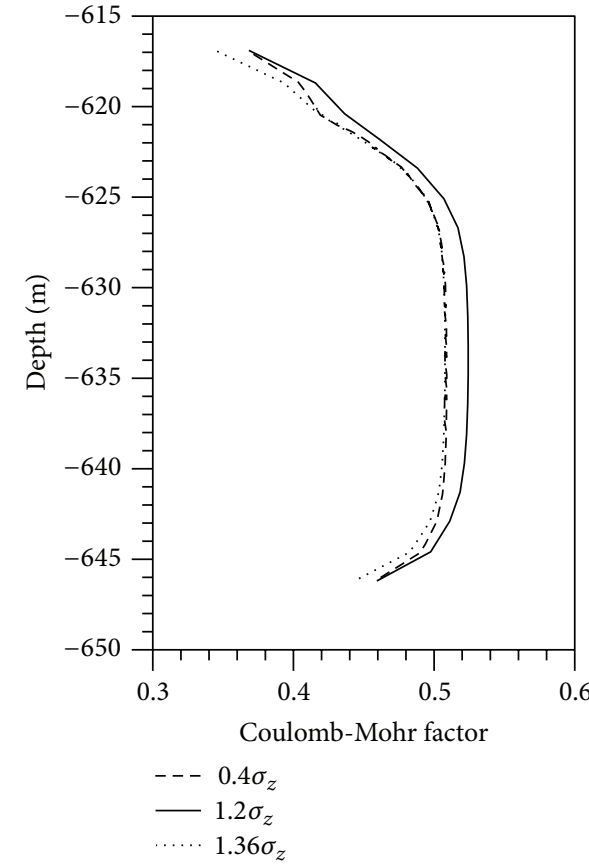

(b)

FIGURE 11: Failure factor according to Burzynski criterion (a) and to Coulomb-Mohr criterion (b) along the chamber wall for the detector chamber in anhydrite [11]. 


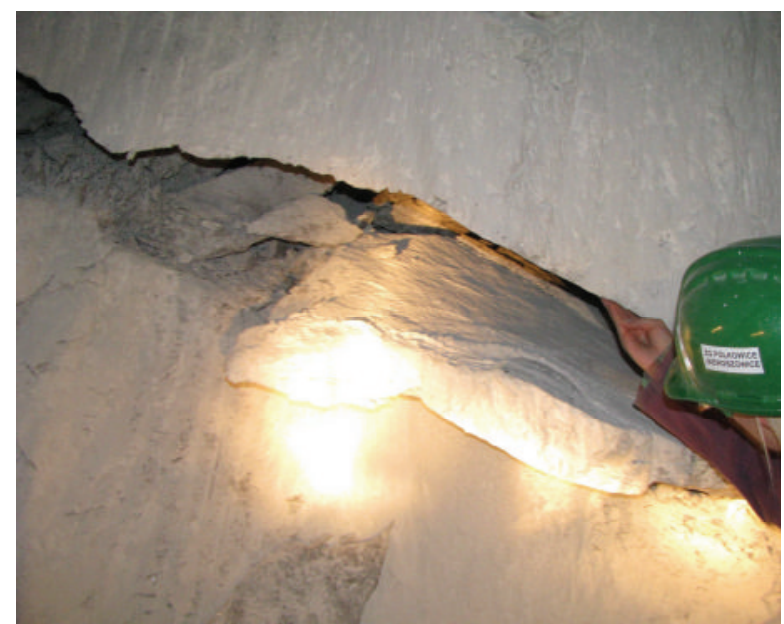

FIGURE 12: Crack in the contact zone of rock salt (a) and anhydrite (b) in the side wall of the Ps-1 gallery [10].

\section{Acknowledgments}

The LAGUNA design study was financed by the FP7 Research Infrastructure "Design Studies" Grant Agreement no. 212343 FP7-INFRA-2007-1. Researches were carried out by MEERI PAS and KGHM CUPRUM CBR. Special thanks are extended to the management of the Polkowice-Sieroszowice copper ore mine, who provided considerable and comprehensive assistance.

\section{References}

[1] A. Rubbia, "The Laguna design study-towards giant liquid based underground detectors for neutrino physics and astrophysics and proton decay searches," Acta Physica Polonica B, vol. 41, no. 7, pp. 1727-1732, 2010.

[2] E. Tziaferi, M. J. Carson, V. A. Kudryavtsev et al., "First measurement of low intensity fast neutron background from rock at the Boulby Underground Laboratory," Astroparticle Physics, vol. 27, no. 5, pp. 326-338, 2007.

[3] L. Mosca, "Fréjus site for the LAGUNA projects," Acta Physica Polonica B, vol. 41, no. 7, pp. 1773-1778, 2010.

[4] L. Labarga, "LAGUNA and the LSC" Acta Physica Polonica B, vol. 41, no. 7, pp. 1765-1772, 2010.

[5] W. H. Trzaska, T. Kalliokoski, and K. Loo, "LAGUNA in Pyhäsalmi," Acta Physica Polonica B, vol. 41, no. 7, pp. 1779-1787, 2010.

[6] W. H. Trzaska, T. Enqvist, J. Joutsenvaara et al., "Advantages of locating LAGUNA in Pyhäsalmi mine," Progress in Particle and Nuclear Physics, vol. 66, no. 2, pp. 463-467, 2011.

[7] S. Arad, V. Arad, I. Onica et al., "Stability study for a large cavern in salt rock from Slanic Prahova," Acta Physica Polonica B, vol. 41, no. 7, pp. 1789-1802, 2010.

[8] A. Zalewska, W. Pytel, M. Chorowski et al., "LAGUNA in Polkowice-Sieroszowice mine in Poland," Acta Physica Polonica B, vol. 41, no. 7, pp. 1803-1812, 2010.

[9] J. Kisiel, M. Budzanowski, J. Dorda et al., "Measurements of natural radioactivity in the salt cavern of the PolkowiceSieroszowice copper mine," Acta Physica Polonica B, vol. 41, no. 7, pp. 1813-1819, 2010.
[10] J. Slizowski, K. Urbanczyk, D. Wiewiorka, M. Kowalski, and K. Serbin, Excavation stability in LGOM bedded evaporates for underground laboratory construction. Monographs no. 168 [M.S. thesis], IGSMiE PAN, Krakow, Poland, 2011.

[11] J. Slizowski, K. Urbanczyk, and K. Serbin, "Salt chamber for the astroparticle detector-LAGUNA project," in Proceedings of the Conference on Mechanical Behavior of Salt VIII, P. Berest, M. Ghoreychi, F. Hadj-Hassen, and M. Tijani, Eds., pp. 209-214, Paris, France, April 2012.

[12] J. Klapcinski and T. M. Peryt, Geology of Przedsudecka Monocline, Monography of KGHM Polska Miedz S.A. (Piestrzynski), Lubin, Poland, 2007.

[13] Laguna Design Study (Sunlab)-Underground Infrastructure and Engineering Interim Report. Report of KGHM Cuprum CBR Wroclaw, KGHM Polska Miedz SA, PolkowiceSieroszowice, IGSMiE PAN Krakow, 2012.

[14] Z. Pilecki, Determination of Rock Mass Parameters Using Geotechnical Classifications, Drukrol, Krakow, Poland, 2002.

[15] N. Barton, Rock Quality, Seismic Velocity, Attenuation and Anisotropy, Taylor \& Francis Group, London, UK, 2007.

[16] J. Slizowski and K. Urbanczyk, Influence of Depth on Rock Salt Effort around the Single Chamber, IGSMiE PAN, Krakow, Poland, 2004.

[17] U. Hunshe, "True triaxial tests on cubic rock salt samplesexperimental methods and results," in Proceedings of the Iutam Symposium on Finite Inelastic Deformations-Theory and Applications, D. Besdo and E. Stein, Eds., pp. 525-536, Hannover, Germany, August 1991.

[18] I. Plischke, "Determination of mechanical homogeneous areas in the rock salt mass using creep properties for a classification scheme," in 6th Conference on the Mechanical Behavior of Salt 'SALTMECH6' - The Mechanical Behavior of Salt - Understanding of THMC Processes in Salt, pp. 321-325, deu, May 2007.

[19] K. H. Lux and S. Heusermann, "Creep test on rock salt with changing load as a basis for the verification of theoretical material laws," in Proceedings of the 6th International Symposium on Salt Symposium, vol. 1, pp. 417-435, Salt Institute, Toronto, Canada, 1883. 

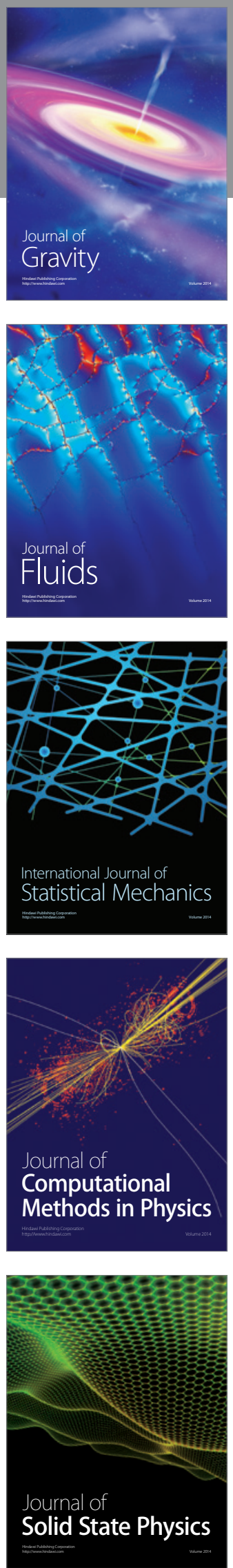

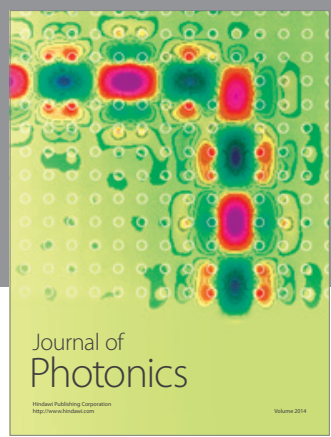

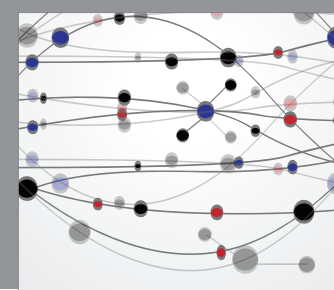

The Scientific World Journal

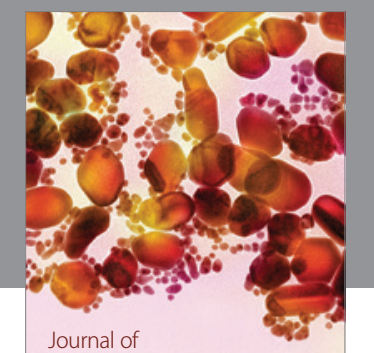

Soft Matter
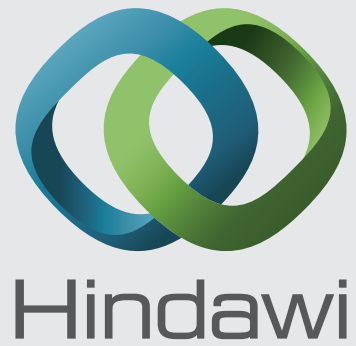

Submit your manuscripts at

http://www.hindawi.com
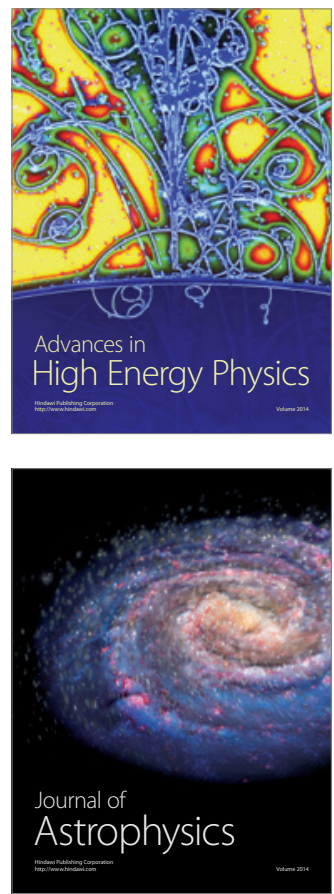
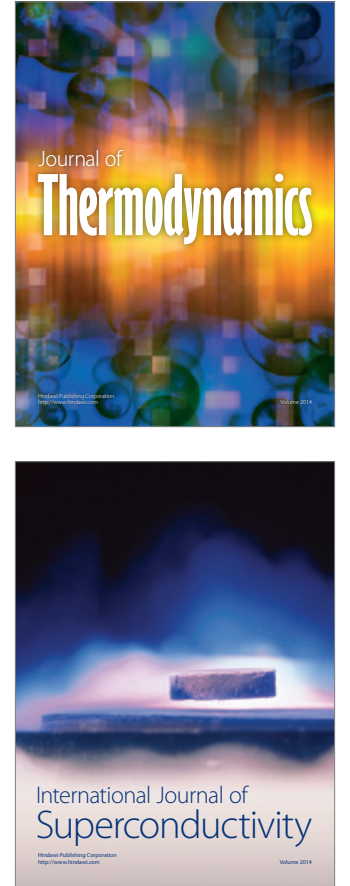
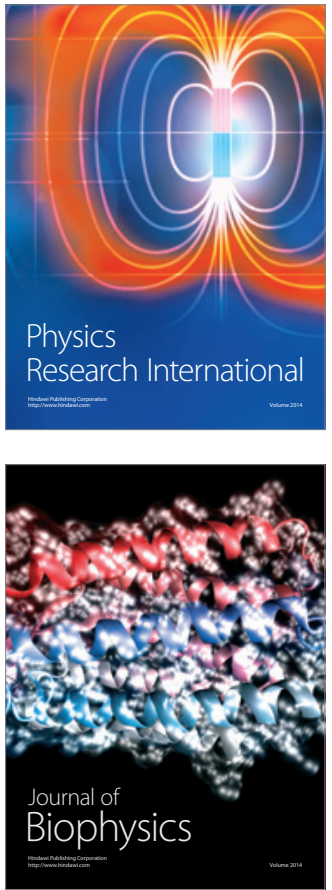
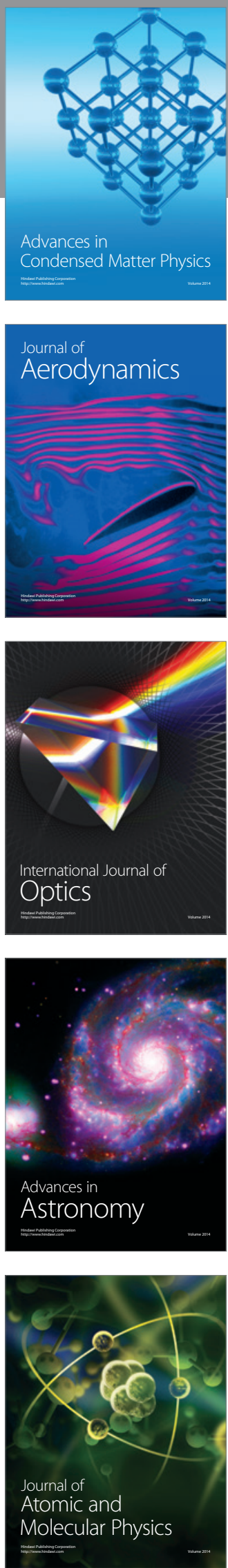